\title{
Water Quality Evaluation and Analysis on the Causes of Pollution for Groundwater Sources in Yantai, China
}

\author{
Panpan Meng ${ }^{1}$, Henghua $\mathrm{Zhu}^{2}$, Jing $\mathrm{Wang}^{3}$ and Baoping $\mathrm{Lv}^{3}$ \\ 1. Geological Environment Monitoring Station of Yantai City, Yantai 264005, Shandong, China \\ 2. Shandong Institute of Geological Survey, Jinan 250014, Shandong, China \\ 3. Shandong Geological Environment Monitoring Center, Jinan 250014, Shandong, China
}

\begin{abstract}
Based on the investigation for the 14 groundwater sources, the water quality of the groundwater sources had been analyzed, using the evaluation method of the combination of inorganic and organic index instead of the traditional method which was only based on inorganic index. The results showed that the quality of 12 groundwater sources satisfied class III standard of groundwater quality and other two exceeded class III standard. There were one groundwater source, whose water quality reached class I standard, and five groundwater sources, whose water quality reached class II standard. There were seven groundwater sources, in which the fluorine, an organic pollutant, was detected. The results showed that the groundwater resources in Yantai City were less polluted and the main pollutant in groundwater was nitrate. According to the analytical data and the environmental conditions of groundwater sources, the conclusion was drawn that the agriculture and rural non-point pollution were the main reasons of groundwater pollution.
\end{abstract}

Key words: Groundwater sources, water quality evaluation, groundwater pollution, organic pollution analysis.

\section{Introduction}

Water is the source of human survival. With population growth and economic development, and traditional concepts of heavy economy and light environmental protection, the current water environment pollution problems are serious [1]. Especially the groundwater pollution problems have become increasingly prominent, groundwater pollution prevention and control situation is grimmer. There are many kinds of pollutants in groundwater and the main pollutants are the inorganic compounds [2]. The study found that there is a certain relationship between the incidence of hypertension and high levels of nitrates in drinking water [3]. Nitrite is a precursor to the synthesis of strong carcinogenic nitrosamines, and it has high correlation with the incidence of gastric cancer [4]. Therefore, the quality of water resources has a direct impact on human health, and all the

Corresponding author: Panpan Meng, master, intermediate engineer, research field: geological environment protection. E-mail: mengpan3205321@163.com. countries in the world have paid close attention to the research of water quality.

Groundwater is an important water source in Yantai, a coastal city of China. The quality of the groundwater environment is directly related with the city's economic development and people's lives. In recent years, with the development of industry and agriculture, water resources in Yantai have been polluted to different degrees. Groundwater evaluation and protection are very important to the sustainable development of Yantai economy. Therefore, to carry out the evaluation of groundwater quality, especially the quality evaluation of groundwater source has an important significance to the rational use of water resources and sustainable development of economy and environment protection in Yantai City.

The groundwater source of Yantai City is located in water-rich region of the valley alluvium and its quantity is abundant. It is buried so shallow with no protection layer that it is susceptible to contamination. Types of groundwater are pore phreatic water and the 
recharge source is mainly meteoric water. Dynamic water level is mainly restricted by amount of precipitation and mining situation. In this paper, 14 representative groundwater sources were selected. Water sources have the double functions of living water and industrial water supply. Distribution of groundwater sources is shown in Fig. 1.

\section{Methodology}

\subsection{The Selection of Evaluation Index}

According to "Investigation and Evaluation of Groundwater Pollution Standards" (DD2008-01) and "Groundwater Quality standards" (GB/T 14848-2007), 48 chemical components closely related to human production and life were selected as the evaluation indexes, including 12 general chemical indicators, five inorganic toxicology indexes, five indexes of heavy metals toxicity (class), 21 volatile organic indexes and five semi-volatile organic indexes (Table 1).

\subsection{Evaluation Methods}

Groundwater quality was evaluated using the noted scoring method of "Groundwater Quality Standards" (GB/T 14848-2007). First of all, the category of each component was divided according to "Groundwater Quality Standards"; secondly, the score of $F i$ of the individual components was determined according to Table 2; thirdly, the comprehensive evaluation score of $F$ was calculated according to Eq. (1); and finally, the level of groundwater quality was determined according to Table 3. If the values of different types were the same, the $F i$ was determined according to the better water quality category.

$$
F=\sqrt{\frac{F_{P}^{2}+F_{\max }^{2}}{2}}, F_{P}=\frac{1}{n} \sum_{i=1}^{n} F_{i}
$$

where, $F$-comprehensive evaluation scores; $F_{p}$-the mean value of each individual component scores of $F i ; F_{\max }$ - the maximum value of single component

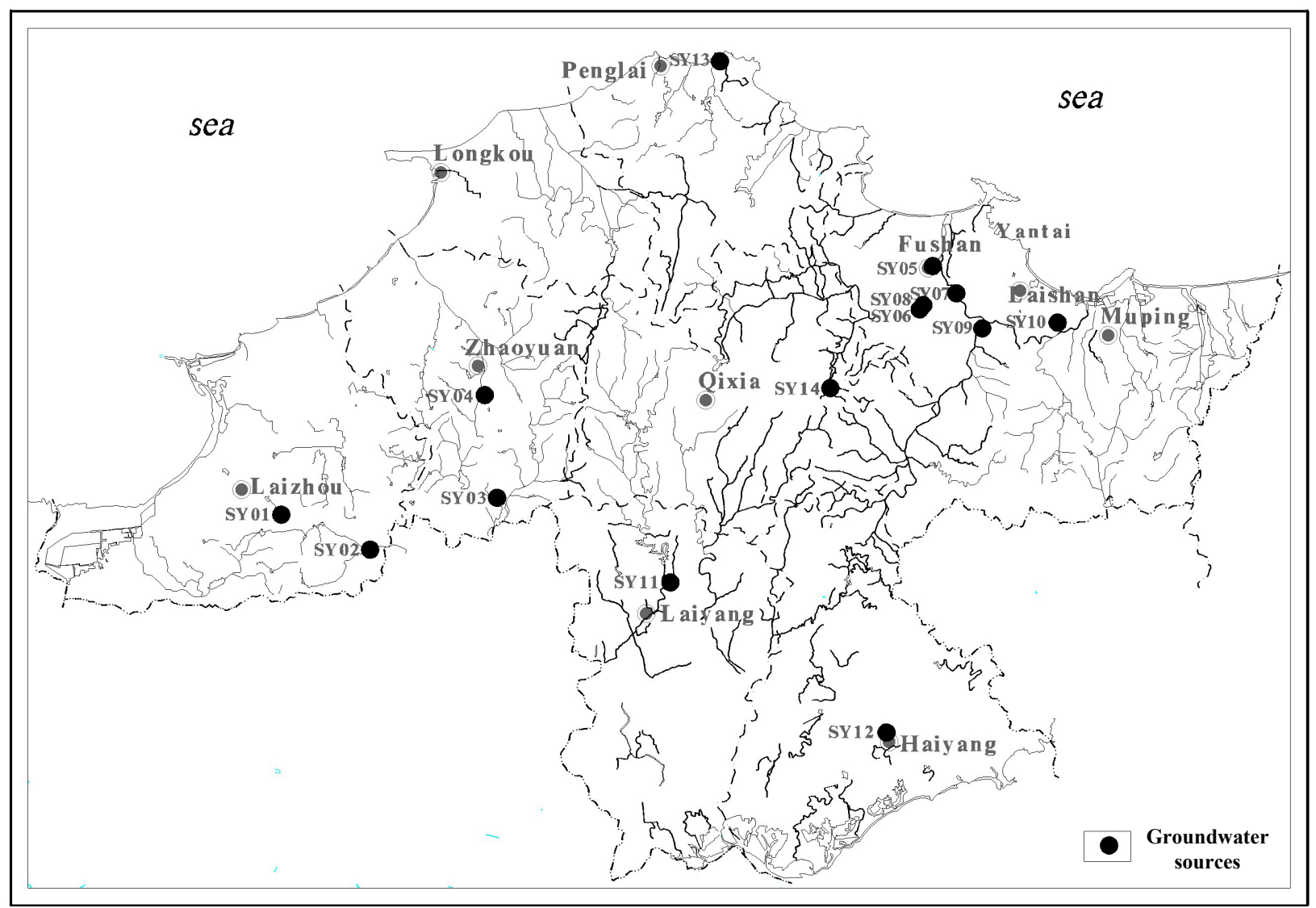

Fig. 1 Distribution of groundwater sources. 
evaluation scores in $F i$; $n$-the number of evaluation items.

\section{Results}

Among the 14 groundwater sources, the water quality of 12 sources reached class III standard of groundwater quality, which account for $85.7 \%$, including one excellent, five good, and six medium. The water quality of the two groundwater sources did not reach the class III standard of groundwater quality, and with $\mathrm{pH}$ and nitrate nitrogen out of control, another was polluted severely by aluminum and nitrate nitrogen. The water quality of the 14 groundwater sources was better than the quality of class $\mathrm{V}$ standard.

Nitrate was the major pollutant of underground water source in Yantai City. There were eight groundwater sources, whose nitrate exceeded class III standard of groundwater quality, which account for $57.1 \%$. The results of groundwater quality evaluation were shown in Table 4, and the nitrate content of groundwater source was shown in Fig. 2.

In organic pollutants analysis, 90 organic compounds were analysed. Among the 14 groundwater sources, where seven water sources detected organic pollutants fluorene, other organic pollutants were not detected.

It can be seen from Fig. 2 that the nitrate content range was between $7.35 \mathrm{mg} \cdot \mathrm{L}^{-1}$ and $99.55 \mathrm{mg} \cdot \mathrm{L}^{-1}$. The nitrate content of eight groundwater sources exceeded the limit value of class III standard of groundwater quality. The maximum nitrogen content was 99.55 $\mathrm{mg} \cdot \mathrm{L}^{-1}$, which originated from SY03, and exceeded the standard 2.25 times. Nitrate content of SY04, SY06, SY08, SY11, SY12, SY13 and SY14 also exceeded the limit value, and the excessive rate was $57.1 \%$.

\section{Discussion}

\subsection{Agricultural Pollution}

In Yantai, the surrounding areas of groundwater sources were mainly used for agricultural planting, and the rural population was more concentrated. Large amounts of chemical fertilizers and pesticides were used. The utilization of chemical fertilizers in China was not actually high as nutrient was absorbed little by plants [5], with the utilization rate of nitrogen only $30 \%-35 \%$, the phosphate $10 \%-20 \%$, and the potash $35 \%-50 \%$. The rest entered the environment through various means, such as runoff, leaching, denitrification, adsorption and erosion.

Table 1 Groundwater quality evaluation index.

\begin{tabular}{|l|l|}
\hline Index classification & The included indicators \\
\hline General chemical indicators (12) & $\begin{array}{l}\mathrm{pH} \text {, iron, manganese, zinc, aluminum, chloride, sulfate ions, total hardness, total dissolved } \\
\text { solids, oxygen consumption, ammonium ions, and sodium }\end{array}$ \\
\hline Inorganic toxicological indicators (5) & Selenium, fluoride, iodide, nitrate, and nitrite \\
\hline Toxicity (class) heavy metal (5) & Arsenic, cadmium, chromium, lead, and mercury \\
\hline Volatile organic index (21) & $\begin{array}{l}\text { Chloroform, carbon tetrachloride, 1,1,1-trichloroethane, trichlorethylene, tetrachlorethylene, } \\
\text { methylene chloride, 1,2-dichloroethane, 1,1,2-trichloroethane dioxane, 1,2-dichloropropane, } \\
\text { bromoform, vinyl chloride, vinylidene chloride, 1,2-dichloroethylene, chlorobenzene, } \\
\text { o-dichlorobenzene, p-dichlorobenzene, benzene, toluene, ethylbenzene, xylene, and styrene }\end{array}$ \\
\hline Semi-volatile organic indicators (5) & Total BHC, $\gamma$-BHC (lindane), total DDT, hexachlorobenzene, and benzo(a) pyrene \\
\hline
\end{tabular}

Table 2 Evaluation of the individual components of the score.

\begin{tabular}{llllll}
\hline Category & I & II & III & IV & V \\
\hline Value $(F i)$ & 0 & 1 & 3 & 6 & 10 \\
\hline
\end{tabular}

Table 3 Groundwater quality evaluation standard.

\begin{tabular}{llllll}
\hline Level & Excellent & Good & Medium & Worse & Worst \\
\hline Value $(F)$ & $F<0.80$ & $0.8 \leq F<2.50$ & $2.50 \leq F<4.25$ & $4.25 \leq F<7.20$ & $F>7.20$ \\
\hline
\end{tabular}


Table 4 Water quality evaluation results.

\begin{tabular}{llllll}
\hline Code & Groundwater source name & Value $(F)$ & Water quality evaluation & Influence index & $\begin{array}{l}\text { Organic } \\
\text { compounds } \\
\text { detected }\end{array}$ \\
\hline SY01 & Liu Jia water source & 2.12 & Good & Fluorene \\
SY02 & Cao river water source & 4.25 & Medium & Fluorene \\
SY03 & Miao Zikuang water source & 7.08 & Worse & $\mathrm{NO}_{3}^{-}$ & ${\text {Aluminum, } \mathrm{NO}_{3}^{-}}^{-}$ \\
SY04 & Shi Xing river water source & 4.25 & Medium & $\mathrm{NO}_{3}^{-}$ & Fluorene \\
SY05 & Fushan water source & 2.12 & Good & $\mathrm{NO}_{3}^{-}$ & \\
SY06 & Mo Tang water source & 4.25 & Medium & & $\mathrm{NO}_{3}^{-}$ \\
SY07 & Tao Kou water source & 2.12 & Good & & Fluorene \\
SY08 & Da Wu water source & 4.25 & Medium & & Fluorene \\
SY09 & The fourth water source of Qingquan & 2.13 & Good & $\mathrm{NO}_{3}^{-}$ & Fluorene \\
SY10 & The second water source of Qingquan & 2.13 & Good & & Fluorene \\
SY11 & Mu Tou water source & 4.25 & Medium & $\mathrm{NO}_{3}^{-}$ & $\mathrm{NO}_{3}^{-}, \mathrm{pH}$ \\
SY12 & East Village water source & 0.71 & Excellent & Medium & \\
SY13 & Changdao water source & 4.25 & 4.25 & Worse & \\
SY14 & Bridge water source & & &
\end{tabular}

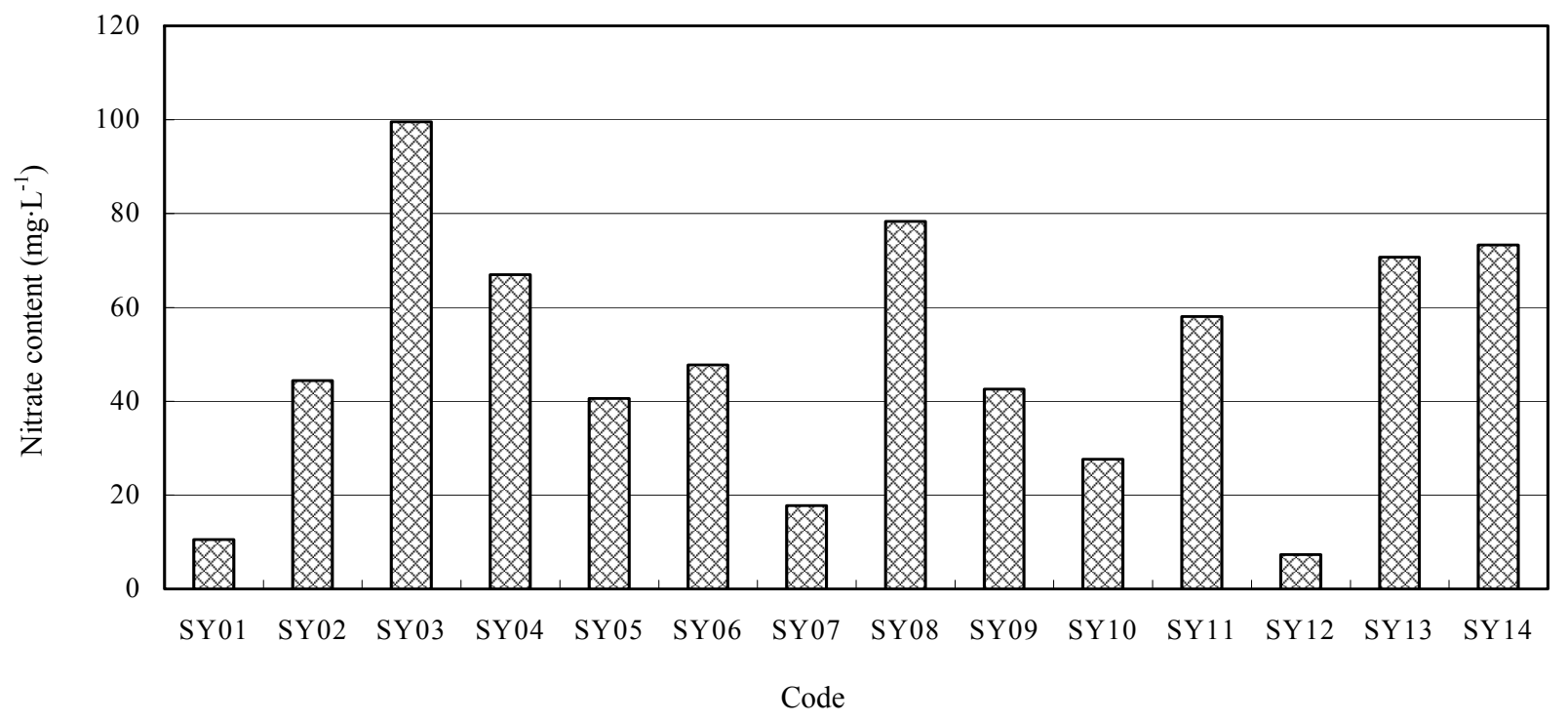

Fig. 2 Nitrate content of groundwater source.

According to Ref. [6], the soil fertilizer leaching into groundwater accounts for about $30 \%-50 \%$ in the whole world. A small amount of unabsorbed nitrogenous fertilizer returns to the atmosphere by evaporation or nitrogen removal. A large number of nitrogenous fertilizers residued in the soil, infiltrated the underground water by precipitation and led to the increase of nitrate content in groundwater. There was a significant positive correlation of groundwater nitrate pollution with nitrogen fertilizer application [6]. Nitrate pollution of groundwater mainly comes from chemical fertilizer and animal manure excessive application [7]. Most of underground water resources in Yantai City were easy to be polluted, owing to flat terrain, shallow buried phreatic aquifer and no protective layer, while a large amount of agricultural fertilizers were used, and nitrogen was extremely easy infiltration to groundwater, so accumulation gradually caused the increase of nitrate in groundwater.

Fluorene detected in groundwater was closely related with the use of pesticides and herbicides in the farmland. Access to relevant information, fluorene is 
an organic material, which was used in the production of pharmaceuticals, dyes, synthetic pesticides and herbicides. Modern agricultural production used a great deal of pesticides and only about $10 \%$ were absorbed by crops [8]. Along with surface runoff, unabsorbed pesticides entered the soil, infiltrated into underground aquifers and caused contamination.

\subsection{Rural Living Garbage and Sewage Infiltration Pollution}

Human life produces large amounts of garbage. Along with the flushing of rainfall and surface flow, the leachate will percolate through the soil. The pollutants into the soil gradually infiltrate the groundwater and pollute the underground aquifers. The main pollutants include carbohydrates, nitrogen, synthetic detergents and a variety of microorganisms [8]. Sewage infiltration is another important cause of groundwater contamination. Sewage which enters the river may infiltrate into the groundwater and cause increase of "three nitrogen", hardness and total dissolved solids content of groundwater.

\subsection{Industrial Pollution}

There were a few groundwater sources located in the more developed industrial area and suburban district of Yantai, such as SY14 and SY10, in which the quality of groundwater source was affected by industrial pollution so inevitably. Despite the strict control of industrial pollution, there were many industrial pollutants in the groundwater, such as SY14, whose aluminum content exceeded class III standard of groundwater quality because of the surrounding enterprises.

\section{Conclusions and Recommendation}

Water quality analysis of groundwater sources in Yantai City indicates:

(1) In Yantai, the quality of groundwater sources was medium, and most of the groundwater sources met the requirements of class III standard of groundwater quality, while a minority of water source quality was poor;

(2) Nitrate pollution in groundwater was universal, the groundwater monitoring well accounted for $57.1 \%$, whose nitrate content exceeded class III standard of groundwater quality. One organic pollutant, fluorine, was detected in groundwater sources. It is necessary that processing nitrate is before water supply;

(3) Human activities were the main reason causing groundwater quality worse, such as industry, agriculture, and rural non-point pollution source;

(4) The groundwater pollution had the characteristics of concealment and difficult to control. In order to ensure water security and human health, in the future, it is necessary to strengthen the propaganda and popularization of scientific knowledge, and the management of water sources ecological environment and rural pollution.

\section{References}

[1] Wang, Z. W. J. 2012. "Analysis of "Three Nitrogen" Pollution of Groundwater in Dalian Center City." China Environmental Monitoring 28 (6): 37-40.

[2] Luo, Z. J., and Jin, M. G. 2002. "Research Progress of Three Nitrogen Pollution of Groundwater." Hydrogeology and Engineering Geology 4: 65-9.

[3] Lv, Y. J. 1998. "Non-point Source Pollution Caused by Nitrogen in Agricultural Ecosystem." Agricultural Environmental Protection 17 (1): 35-9.

[4] Zhang, R. B. 1979. "Study on the Etiology of Gastric Cancer." Foreign Medical Reference Oncology 3: 107-14.

[5] Tang, L., Bai, D., and Jiang, R. F. 2003. "Non-point Source Pollution of Agriculture and Pollution Prevention and Control of Groundwater." Soil and Water Conservation Research 10: 212-4.

[6] Yi, X. J. 1991. "Study on the Leakage of Nitrogen Fertilizer." Agricultural Environmental Protection 5: 223-6.

[7] Huang, M. S. 1995. "A Brief Discussion on the Nitrogen Pollution of Groundwater and Its Prevention Measures." Shanghai Environmental Sciences 14: 26-8.

[8] Dong, L., and Liu, H. 2013. "Analysis of the Main Ways of Groundwater Pollution, Harm and Prevention." West China Exploration Engineering 6: 149-53. 